\title{
La orilla latinoamericana. Imperialismo, migración y la nueva condición latinoamericana
}

Desde hace algunos años, México enfrenta una difícil y compleja situación respecto a su condición latinoamericana. Por un lado, la acelerada norteamericanización de sus modelos culturales y el giro conservador de su poder político dominante se sustentan en una tendencia que desde 1994, con el Tratado de Libre Comercio firmado con Estados Unidos y Canadá, se quiere instaurar como definitiva: pensarnos y planear nuestro futuro a la sombra del imperio, lo que implicaría tomar distancia del nuevo ciclo de organización política y social que experimenta América Latina. Por otro lado, esta reorganización geopolítica y cultural que experimenta el subcontinente en los últimos años, parece que exige de nuestro país una reconsideración sobre su locus latinoamericano, es decir, nos orilla a pensarnos estratégicamente como latinoamericanos y a revisar los múltiples

75 Narrador y ensayista mexicano. 
pasados que marcan nuestras cercanías y desencuentros con los países de la región.

Esta ambigüedad la podemos resumir en algunos planteamientos geopolíticos que expresan la complejidad del asunto y que nos colocan en varias encrucijadas. Uno de ellos parece decir lo siguiente: o aceleramos nuestra integración subordinada y dependiente con los Estados Unidos y nos convertimos en un país del norte donde se diluye -y a veces hasta se impone- el límite de América Latina, o nos asumimos como la frontera latinoamericana con los Estados Unidos, es decir, el sur del imperio, lo que implicaría revalorar la posibilidad de integrar un bloque latinoamericano que nos permita enfrentar con mayores ventajas la cercanía con el imperio. En el nuevo mapa de la globalización capitalista y militar, cultural y económica, en la cartografía Norte-Sur, el lugar de México se percibe todavía incierto.

Quiero abordar en estas líneas dos problemas que considero fundamentales para reflexionar sobre esta compleja relación entre México y el resto de América Latina. El primero sería el de las migraciones latinoamericanas hacia diferentes partes del mundo, especialmente hacia los Estados Unidos, migración que por sus alcances y complejidad ha sido objeto de una amplia revisión en los últimos años. Además, me parece que es necesario plantear la relación de América Latina, y por añadidura la de México con los Estados Unidos, en los términos de un nuevo e inédito colonialismo, lo que implicaría dotar de nuevo significado al concepto de imperialismo y repensar las políticas de intervención y legitimación emprendidas en los últimos años por los Estados Unidos.

Los sujetos migrantes y la modernización neoliberal

En uno de los últimos ensayos que publicó en vida Antonio Cornejo Polar -titulado "Una heterogeneidad no 
dialéctica: sujeto y discurso migrantes en el Perú Moderno"-, al analizar cómo se representaba en la literatura peruana la migración que iba del campo a la ciudad y que fue uno de los procesos de larga duración que modificaron drásticamente la configuración del espacio latinoamericano, el crítico peruano proponía el concepto de sujeto migrante como alternativa para interpretar dicho fenómeno y su escenificación en la literatura peruana del siglo XX.

Me parece que es posible utilizar el concepto de sujeto migrante para entender otro tipo de migración -la del exilio económico de millones de latinoamericanos hacia los Estados Unidos- y al mismo tiempo localizar la emergencia de larga duración de un sujeto político y cultural cuya heterogeneidad se debate entre dos extremos: por un lado, la situación marginal y frágil ante las políticas agresivas y excluyentes de los Estados Unidos, la persecución y la ilegalización permanente de su situación de frontera, que también configura una poderosa dimensión narrativa cultural; por el otro, la utopía de una integración frenética a los modelos de idealización de la vida en los Estados Unidos, cuyos relatos actualizan política y sentimentalmente la vieja retórica del sueño americano.

Además, para Cornejo Polar, la caracterización de un sujeto migrante y de su condición discursiva significa la oportunidad de renunciar a las interpretaciones armoniosas de los fenómenos migratorios contemporáneos, como la del mestizaje o la de la una lectura conservadora de transculturación, o la de ciertas nociones de los estudios culturales:

"Mi hipótesis primera tiene que ver con el supuesto de que el discurso migrante es radicalmente descentrado, en cuanto se construye alrededor de ejes varios y asimétricos, de alguna manera incompatibles y contradictorios de un modo no dialéctico. Acoge no menos 
de dos experiencias de vida que la migración, contra lo que se supone en el uso de la categoría de mestizaje, y en cierto sentido en el del concepto de transculturación, no intenta sintetizar en un espacio de resolución armónica; imagino - al contrario- que el allá y el aquí, que son también el ayer y el hoy, refuerzan su aptitud enunciativa y pueden trabar narrativas bifrontes y -hasta, si se quiere, exagerando las cosas- esquizofrénicas. Contra ciertas tendencias que quieren ver en la migración la celebración casi apoteósica de la desterritorialización (García Canclini), considero que el desplazamiento migratorio duplica (o más) el territorio del sujeto y le ofrece o lo condena a hablar desde más de un lugar. Es un discurso doble o múltiplemente situado".

Retomando la terminología de Cornejo Polar, ¿desde dónde han hablado los últimos gobiernos mexicanos en relación con el fenómeno migratorio y sus consecuencias para América Latina? Todo parece indicar que la subordinación estratégica a las políticas de frontera de los Estados Unidos, derivada también de la implementación acelerada de una modernización neoliberal que apostaba a la fragmentación paulatina de América Latina como bloque económico, político y cultural, ha puesto muchas veces al límite la condición latinoamericana de nuestro país. Por ejemplo, el proyecto de hacer de México la frontera del Norte y servir como escudo ante la migración centroamericana fue una expresión de esta servidumbre estratégica, que se intenta resolver en una extensión fronteriza del Imperio del territorio mexicano. Además, el Tratado de Libre Comercio de América del Norte se ha transformado en un instrumento de dominio económico que tiende un cerco sobre México: la norteamericanización de nuestra economía no ha generado la 
ilusoria capitalización del país, más bien se ha definido a partir de su sometimiento como horizonte de mercado, como un espacio transnacional de consumo, aislándonos además del resto de América Latina.

Hablar y actuar desde la servidumbre estratégica no ha redituado los resultados esperados. La militarización de la frontera México-Estados Unidos y la renuncia sistemática del imperio a concretar un acuerdo migratorio que legalice a millones de mexicanos han demostrado que la servidumbre tiene límites. Esta situación ha colocado a México en una especie de limbo cultural y político. Es imposible una integración armoniosa y no traumática al imperio, más bien, es necesario reconocer que las políticas de los Estados Unidos tienen como base la paulatina devastación de los dominados y socios, su inserción servil y sistemáticamente controlada a la lógica militar y económica que rige su proceso de acumulación capitalista. No se ha dado la integración frenética y alegre al imperio prevista por los tecnócratas, con un Estado mexicano controlado y semicolonizado por instrumentos económicos como el Tratado de Libre Comercio; al contrario, nos hemos instalado en una distancia e indiferencia a veces feroz hacia los ciclos de integración regional que actualmente se experimentan en América Latina.

Quisiera no perder de vista el resorte básico del exilio económico: la pauperización permanente de las sociedades latinoamericanas. El discurso de la servidumbre estratégi$\mathrm{ca}$, en sus momentos de mayor densidad, exalta ei nacionalismo cultural y los atributos morales y laborales de los migrantes por encima de la tendencia de control y aniquilación de los Estados Unidos hacia la migración. Además, este discurso se ha construido sobre un olvido: el aumento de la migración latinoamericana hacia los Estados Unidos se da precisamente en los momentos de aplicación de un neoliberalismo intensivo en nuestros países. 


\section{En el nombre del capital y la democracia: otra vez el imperio}

¿Es posible hablar de políticas exterior y militar de los Estados Unidos en los términos de imperialismo y colonialismo? ¿Por qué retomar conceptos que parecían ya superados, precisamente ahora que el discurso político dominante celebra la expansión del libre mercado y la modernización neoliberal como evidencias de la derrota definitiva de toda utopía con rasgos comunitarios o sociales?

El intelectual palestino Edward W. Said ha planteado que la política internacional de los Estados Unidos puede ser definida y entendida actualmente con el concepto de imperio: en sus narraciones políticas y en sus relatos culturales se expresa también una continuidad colonial configurada durante los siglos XIX y XX. Para Said, las políticas de interpretación colonial no terminaron con la descolonización burocrática, militar y territorial de los últimos territorios sometidos en Asia, África y América Latina.

Después de la caída de la Unión Soviética, un nuevo modo de colonización se impuso casi invisible en medio de la celebración de las libertades políticas instauradas en países que pertenecían al bloque soviético. Una colonización que no surgió de manera espontánea, sino que fue gestada de las décadas del 60 y 70. La brecha entre países ricos y pobres sirvió para establecer los nuevos mecanismos de la dominación imperial, una dominación que hasta el año 2001 parecía imposible de rastrear. Después del 11 de setiembre de 2001, del ataque a las Torres Gemelas y de las invasiones a Afganistán e Irak en nombre de la instauración occidental de la democracia en contextos periféricos, la convicción imperial de los Estados Unidos quedó más clara que nunca.

Dice Noam Chomsky: 
"El conflicto Sur-Norte no decrecerá, y tendrán que idearse nuevas formas de dominación para asegurar que los sectores privilegiados de la sociedad industrial occidental mantengan un control sustancial sobre los recursos mundiales, tanto humanos como materiales, y que gracias a este control se beneficien de un modo desproporcionado. De ahí que no sea ninguna sorpresa el hecho de que la reconstrucción de la ideología en Estados Unidos encuentre ecos en el mundo industrializado... Pero uno de los requisitos básicos en el sistema ideológico occidental es que se establezca un abismo entre el Occidente civilizado, con su tradicional compromiso con la dignidad humana, la libertad y la autodeterminación, y la brutalidad bárbara de aquellos que por algún motivo -quizás debido a genes defectuosos- no sean capaces de apreciar la profundidad y la importancia de este compromiso histórico, que tan claramente se revela en las guerras de Norteamérica en Asia".

¿Qué perspectiva ha adquirido el Estado mexicano ante este discurso norteamericano que enaltece la instalación, a "como dé lugar", de la democracia y el libre mercado? ¿Cómo se perfila la articulación o desarticulación de América Latina ante este panorama de cuño imperialista?

Aventuro una hipótesis: la servidumbre estratégica del Estado mexicano hacia Estados Unidos se puede ver como un ejemplo de los términos en que se está llevando a cabo una política de asimilación colonial, que bajo la idea "indiscutible" de la democracia formal única de democratización y libre mercado como única alternativa en la relación Estado-sociedad, estaría configurando un olvido que expresaré con una alegoría escatológica: después de devorarnos política y culturalmente, el estómago del imperio 
nos devuelve bañados en los jugos gástricos de la ensoñación, la marginación y la persecución.

Sin embargo, atrapados en la ilusión de una servidumbre estratégica que obtiene beneficios mínimos, podemos recordar también nuestra condición de fantasmas del Tercer Mundo y transformar este recuerdo en una débil esperanza: seguimos siendo parte de la orilla latinoamericana, solo que ahora es más nítida y de alguna manera novedosa nuestra condición de sujetos migrantes. Pertenecemos a una América Latina nómada, que jamás se ha circunscrito a las identidades dominantes y al aislamiento cultural, político y económico. De otras maneras, es posible ser latinoamericano sin dejar de relatar nuestra plenitud y ruina desde otros lugares. Compartimos, por enésima vez en nuestra historia, la miseria y la migración, el rechazo y la ilegalidad en las entrañas del imperio, el autoritarismo de la modernización neoliberal en contextos periféricos y una leve esperanza de reconocimiento regional y de integración inédita.

\footnotetext{
(ivi) Pudicicicitames

Impreso por el Programa de Publicaciones e Impresiones de la

Universidad Nacional, en el mes de agosto del 2010.

La edición consta de 600 ejemplares.

en papel bond y cartulina barnizable.
} 